\title{
Lusioersily
}

\section{Highly Sensitive SERS Detection of Neonicotinoid Pesticides. Complete Raman Spectral Assignment of Clothianidin and Imidacloprid}

Creedon, N., Lovera, P., Moreno, J. G., Nolan, M., \& O'Riordan, A. (2020). Highly Sensitive SERS Detection of Neonicotinoid Pesticides. Complete Raman Spectral Assignment of Clothianidin and Imidacloprid. The journal of physical chemistry. A, 124(36), 7238-7247. https://doi.org/10.1021/acs.jpca.0c02832

Link to publication record in Ulster University Research Portal

\section{Published in:}

The journal of physical chemistry. A

Publication Status:

Published (in print/issue): 10/09/2020

DOI:

10.1021/acs.jpca.0c02832

\section{General rights}

Copyright for the publications made accessible via Ulster University's Research Portal is retained by the author(s) and / or other copyright owners and it is a condition of accessing these publications that users recognise and abide by the legal requirements associated with these rights.

\section{Take down policy}

The Research Portal is Ulster University's institutional repository that provides access to Ulster's research outputs. Every effort has been made to ensure that content in the Research Portal does not infringe any person's rights, or applicable UK laws. If you discover content in the Research Portal that you believe breaches copyright or violates any law, please contact pure-support@ulster.ac.uk. 


\title{
Highly Sensitive SERS Detection of Neonicotinoid Pesticides. Complete Raman Spectral Assignment of Clothianidin and Imidacloprid
}

\author{
Niamh Creedon ${ }^{1}$, Pierre Lovera ${ }^{1}$, Julio Gutierrez M oreno ${ }^{2}$, M ichael Nolan ${ }^{2}$ and \\ Alan O'Riordan ${ }^{1 *}$ \\ 1: Nanotechnology Group, Tyndall National Institute, University College Cork, Lee M altings, \\ Cork, T12 R5CP, Ireland. \\ 2: Materials M odelling for Devices Group, Tyndall National Institute, University College Cork, \\ Lee M altings, Cork, T12 R5CP, Ireland. \\ E-mail: alan.oriordan@tyndall.ie
}

\begin{abstract}
:
The use of Surface Enhanced Raman Spectroscopy in the development of low cost, portable sensor devices that can be used in the field for nitroguanidine neonicotinoid insecticide detection is appealing. However, a key challenge to achieving this goal is the lack of detailed analysis and vibrational assignment for the most popular neonicotinoids. To make progress towards this goal, this paper presents an analysis of the bulk Raman and SERS spectra of two neonicotinoids, namely clothianidin and imidacloprid. Combined with first principles simulations, this allowed assignment of all Raman spectral modes for both molecules. To our knowledge, this is the first report of SERS analysis and vibrational assignment of Clothianidin and a comprehensive assignment and analysis is provided for imidacloprid. Silver nanostructured surfaces were fabricated for qualitative SERS analysis, which provides the characteristic spectra of the target molecules, and demonstrates the ability of SERS to sense these molecules at concentrations of $1 \mathrm{ng} / \mathrm{mL}$. These concentrations are on a par with high-end chromatographic-mass spectroscopy laboratory methods. These SERS sensors thus allow for the selective and sensitive detection of neonicotinoids, and provides complementary qualitative data for the molecules. Furthermore, this technique can be adapted to portable devices for remote sensing applications. Further work focuses on integrating our device with an electronics platform for truly portable residue detection.
\end{abstract}




\section{Introduction}

The requirements for pest control in intensive agriculture systems has driven the grow th of insecticide use within the agri-sector. In this regard, neonicotinoids are a relatively powerful class of insecticide. Imidacloprid was introduced in 1991 and the neonicitinoids have been the fastest-growing class of insecticides in modern crop protection, ${ }^{1}$ taking ca. $17 \%$ of the global insecticide market. ${ }^{2}$ Neonicotinoids target the nicotinic acetylcholine receptors in insects ${ }^{3}$ and are extremely effective against herbivorous insects. The perceived low toxicity to mammals, birds and fish, ${ }^{4}$ led to their widespread uptake for use on a variety of crops.

However recent years have seen significant concerns raised about the environmental impact of neonicotinoids on the global pollinator population, including honey bees, bumble bees and solitary bees. It is claimed that neonicotinoids affect the homing capacity of honey bees and their reproductive ability with the result of colony collapse disorder. ${ }^{5-6}$ Another emerging concern is that human exposure to these pesticides may increase the prevalence of some cancers, ${ }^{7-8}$ respiratory diseases ${ }^{9-10}$ and damage to the reproductive system, nervous system and liver ${ }^{11-12}$, while children are particularly at risk. ${ }^{13}$ As a consequence, this class of insecticides has become the subject of a world-wide debate. ${ }^{14-}$ 15 The European Food Safety Authority (EFSA), recognising the potential threat caused by neonicotinoids, enforced a temporary ban by the European Union in $2013 .{ }^{16}$ The maximum allowable residue limits of neonicotinoids was set to between 0.01 and $3 \mathrm{mg} / \mathrm{kg}$ for many fruits and vegetables. ${ }^{17-}$

18 Ecological and human health risk assessments for selected neonicotinoids, Imidacloprid and Clothianidin were reviewed by the EFSA in 2018 and the assessment concluded that the use of neonicotinoid pesticides on outdoor crops presents a risk to wild bees and honeybees. ${ }^{19}$ Consequently, in 2019, EU governments passed a near-total ban on the use of active neonicotinoid pesticides including clothianidin and imidacloprid on outdoor crops due to their impact on pollinators. To effectively enforce this ban the development of easy-to-use and low maintenance portable sensor devices is required to enable rapid and reliable decentralised detection of these pesticides.

Current techniques for the detection of neonicotinoids include both chemical and optical detection methods: enzyme linked immuno-sorbent assays (ELISA), ${ }^{20-21}$ HPLC- or GC- mass spectrometry, ${ }^{17,22-25}$ voltammetric methods, ${ }^{26-29}$ and fluorescence spectroscopy. ${ }^{30}$ While these techniques can detect insecticides at low concentrations (low parts per billion), the associated instruments are complex, have a high cost of ownership and are cannot be used for remote field analysis. To permit rapid detection of these neonicotinoids in the field (in situ) necessitates the development of portable, low cost sensor devices. This can be realised using a single optical technique, namely surface enhanced Raman spectroscopy (SERS), which permits the necessary sensitive detection of the target species, 
and trace analyte detection. Raman spectroscopy uses the vibrational properties of the compounds of interest, providing a spectral finger print of the molecule. ${ }^{31-35}$ SERS enhancement occurs at nanostructured plasmonic surfaces following illumination with monochromatic radiation which arises from (i) an increase in local electromagnetic field strengths of localized surface plasmons (in nanogaps between metal clusters called "hot spots") and (ii) chemical resonant energy charge transfer In addition, SERS provides high sensitivity, rapid analysis time and little background interference from water molecules.

With this in mind, the present paper focuses on the development and use of SERS for the detection of the neonicotinoids clothianidin and imidacloprid as test cases for the wider application of SERS as a suitabledetection techniques for neonicotinoids. Bulk Raman studies were performed to explore the characteristic Raman modes to give a fingerprint for both molecules. A silver nanostructured polymer substrate was fabricated for SERS characterisation, which provides physical data (vibrational spectrum) for the insecticide solutions. Molecular identification was verified using SERS together with high level density functional theory simulations. This SERS sensor can be adapted for use in a single portable device. Integration into a portable device is beyond the scope of this paper which aims to demonstrate the ability of SERS to discriminate between the molecules of interest at very low concentrations ( $1 \mathrm{ng} / \mathrm{mL}$ ) that are competitive with, or better than other technologies.

\section{Experimental}

\subsection{Materials and Reagents}

Polyvinylidene fluoride (PVDF), silver wire, imidacloprid and clothianidin were purchased from SigmaAldrich and used as received. Deionized water $(18.2 \mathrm{M} \Omega \mathrm{cm})$ from an ELGA Pure Lab Ultra system was used for the preparation of samples.

\subsection{SERS Substrate Fabrication}

PVDF was selected as we have previously shown that the polymer exhibits superior adhesion to silver, compare to other polymers and very good optical transparency. Pellets of PVDF were placed on a microscope slide and melted on a hotplate at $\sim 220^{\circ} \mathrm{C}$. An aluminium (Al) master template was prepared as previously described by Creedon et al. ${ }^{36}$. The Al master was placed onto the melted droplet and pushed downward so the PVDF wetted the AI surface. The glass slide was removed from the hotplate and the PVDF was peeled from both the glass slide and Al template, to yield a 
nanostructured polymer base. To complete the substrate fabrication, a thin silver layer ( $30 \mathrm{~nm}$ ) was

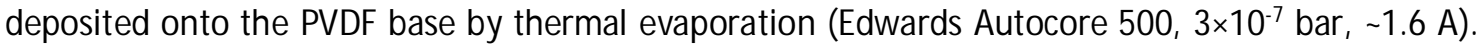
The thickness and the deposition rate were controlled in situ using a calibrated quartz microbalance.

\subsection{Microscopic and Raman Characterisation}

Optical micrographs were acquired using a calibrated microscope (Axioskop II, Carl Zeiss Ltd.) equipped with a charge-coupled detector camera (CCD; DEI-750, Optronics). Scanning electron microscopy analysis was undertaken to characterize the SERS sensor surface after the fabrication procedure. SEM images were acquired using a calibrated field emission SEM (JSM -7500F, JEOLUK Ltd.) operating at beam voltages between 3 and $5 \mathrm{kV}$. All Raman measurements were recorded using a Confocal Renishaw Raman M icroscope equipped with a $514 \mathrm{~nm}$ Ar ion laser and analysed using Wire 3.0 computer software. The laser spot diameter was $\sim 1 \mu \mathrm{m}$ at the substrate surface and a laser power density of $\sim 7 \times 10^{4} \mathrm{~W} / \mathrm{cm}^{2}$ was used. SERS spectra collected using a 50x magnification (0.75 NA) objective microscope, with a data acquisition time of $10 \mathrm{~s}$, over an extended spectral range of $200 \mathrm{~cm}$ 1 to $3500 \mathrm{~cm}^{-1}$. The spectrometer was equipped with a computer controlled motorised XYZ stage employed to focus and adjust the positioning of the sample on the silver surface. Subtraction of the baseline was performed on all spectra to eliminate background noise from the underlying polymer and the recorded spectra were imported into Origin ${ }^{\circledR} 7.4$ (OriginLab) to facilitate data analysis.

\subsection{Computational Methodology}

Density functional theory (DFT) calculations were undertaken to find the equilibrium molecular structures and aid the assignment of the Raman modes of the isolated imidacloprid and clothianidin molecules. The hybrid exchange-correlation functional B3-LYP, using Becke's three parameter exchange and Lee-Yang-Parr correlation ${ }^{37}$ was used al ong with a triple- $\zeta$ valence basis set which has two sets of polarization functions, TVZPP ${ }^{38}$. These are implemented in the Turbomole 6.4 code. $^{39}$ The dispersion forces were corrected by the Grimme's DFT-D3 method. ${ }^{40}$ Redundant internal coordinates were used for the geometry optimization with energy and gradient convergence criteria of less than $10^{-6}$ Hartree and 0.002 Hartree/Bohr. ${ }^{41}$ Force constant calculations were implemented to estimate the vibrational modes of the isolated imidacloprid and clothianidin molecules and harmonic vibrational frequencies were estimated by the analytical evaluation of second derivatives of the energy. ${ }^{42-43} \mathrm{~A}$ scaling factor of 0.9669 was applied to the fundamental vibrational frequencies to correct for the error due to the harmonic approximation in the theoretical model. ${ }^{44}$ 


\subsection{Analysis of Neonicotinoids}

Working solutions of both imidacloprid and clothianidin were prepared in a methanol- DI water solution (1:1) and diluted to $10 \mu \mathrm{g} / \mathrm{mL}$ and $1 \mathrm{ng} / \mathrm{mL}$ concentrations. Solutions were then deposited (50 $\mu$ l) via a drop/dry process onto the SERS substrates (10 $\mathrm{min}$ ). All samples were thoroughly rinsed with DI water before Raman analysis to remove unadsorbed, clumped molecules that accumulated on the surface of the substrate during the drying process. Bulk Raman spectra were also acquired for both molecules. In this work, all wavenumbers in the discussion section are related to the Raman spectra, unless otherwise stated.

\section{Results and Discussion}

\subsection{SERS substrate Characterisation}

A typical SEM micrograph of a portion of a fully prepared PVDF substrate, following Ag deposition, is shown in Figure 1. From SEM analysis the size distribution of the Ag nano-structures is estimated at $60 \pm 20 \mathrm{~nm}$ while the gaps between the clusters are ca. $10 \pm 5 \mathrm{~nm}$. The small separation between $\mathrm{Ag}$ clusters delivers a high yield of electromagnetic hot-spots, making them very attractive and suitable for SERS sensing. A model compound, crystal violet, was analysed to characterise the SERS capabilities of the substrate and the results of this characterisation are presented in Supp. Info (Figure S1), while further substrate characterisation was explored in significant detail ${ }^{36}$ These substrates demonstrated high sensitivity to crystal violet yielding enhancement factors of $\sim 10^{6}$. In previous work, we have shown that the nanostructured surface is 3D in nature, and this topography is required to yield a SERS response from the substrate. No SERS response was observed for CV on planar (non-structured) silver substrates Ref. (35).

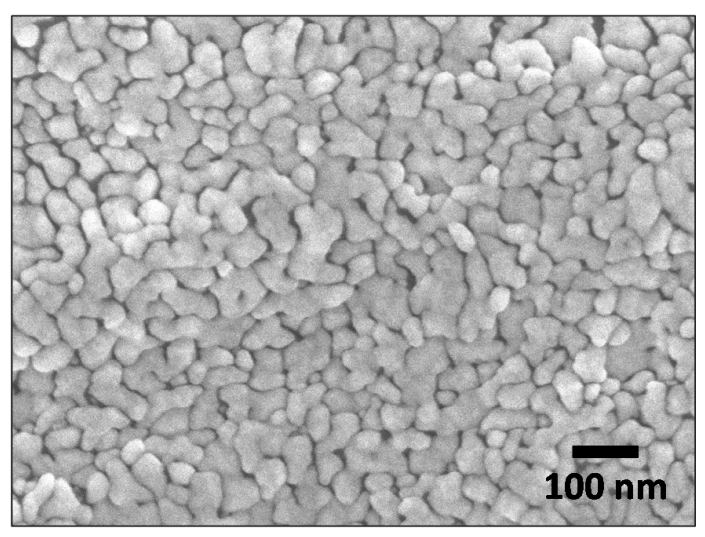

Figure 1: SEM image of a portion of the fabricated SERS substrate silver surface. 


\subsection{Raman and SERS Analysis of Clothianidin}

Bulk Raman spectra were first acquired for Clothianidin and the Raman spectrum is shown in Fiqure $2 a$, exhibiting all the expected characteristic peaks of this molecule. Clothianidin consists of a chlorothiazole ring linked by a carbon to a nitroguanidine structure. The strongest Raman peaks were identified and assigned to their corresponding vibrational modes by visualization of the vibrational modes from the DFT calculations and comparison to the corresponding vibrations in similar molecules in the literature ${ }^{45-46}$ and the assignments are shown in Table 1. In general, the scaled DFT frequencies for the vibrational modes are in good agreement with the experimental vibrational frequencies. The full set of Raman assignments for Clothianidin are discussed in detail in the Supporting Information (SI, Section S2). Although we did not model the explicit interaction of the target molecules with silver surfaces as the focus of the modelling was on the assignment of the Raman modes, we expect from previous work, that the interaction is physisorption or weak chemisorption, as the Raman spectra indicate that molecules are not dissociated or strongly distorted ${ }^{47}$. We note that here are some spectral differences in the peaks observed in Figure $2 \mathrm{a}$ and Figure $2 \mathrm{~b}$ where there is a change in relative intensities and/ or a shift in wavelength. We speculate that these are due to how the molecule attaches to the surface. Adsorption of the molecules is known to change the energy of the molecule and disrupt the vibrational modes, thus shifting peaks and increasing or decreasing peak intensities ${ }^{48}$. The structure of clothianidin together with the atomic numbering used in the later discussion is given in Figure 2c.

\section{C-H vibrations}

The $\mathrm{C}-\mathrm{H}$ stretching vibrations observed in the spectral range from $\sim 3000-3600 \mathrm{~cm}^{-1}$ are presented in Table S1 (SI, Section 2) and we discuss the most relevant modes here. The Raman band at $3121 \mathrm{~cm}^{-1}$ is assigned to the $\mathrm{C}-\mathrm{H}$ stretch in the chlorothiazole ring, $\mathrm{C} 13-\mathrm{H} 19$. There are in-plane bending vibrations associated with $\mathrm{C} 13-\mathrm{H}$ at $1532 \mathrm{~cm}^{-1}, 1296 \mathrm{~cm}^{-1}, 1248 \mathrm{~cm}^{-1}$ and $1152 \mathrm{~cm}^{-1}$. The out of plane wagging modes for $\mathrm{C} 13-\mathrm{H}$ are observed at $871 \mathrm{~cm}^{-1}$ and $669 \mathrm{~cm}^{-1}$. The $\mathrm{C} 10-\mathrm{H}$ symmetric and asymmetric stretching modes are observed at $2965 \mathrm{~cm}^{-1}$ and $3011 \mathrm{~cm}^{-1}$, respectively and the bending mode is at $1462 \mathrm{~cm}^{-1}$. Multiple out of plane twisting modes were found at $1422 \mathrm{~cm}^{-1}$, and $1051 \mathrm{~cm}^{-1}$. Finally, Raman bands at $947 \mathrm{~cm}^{-1}, 669 \mathrm{~cm}^{-1}$ and $259 \mathrm{~cm}^{-1}$ can be assigned to the in-plane rocking of $\mathrm{H} 16$ and $\mathrm{H} 17$ with $\mathrm{C} 10$. The methyl $\mathrm{C}-\mathrm{H}$ symmetric and asymmetric stretching modes are observed at 
$2860 \mathrm{~cm}^{-1}$ and $2900 \mathrm{~cm}^{-1}$, respectively, while the in-plane bending and wagging modes of methyl are found at $1422 \mathrm{~cm}^{-1}$ and $992 \mathrm{~cm}^{-1}$.

\section{Ring Vibrations}

C-C and N-C stretching modes are found at at $1532 \mathrm{~cm}^{-1}$ and $1433 \mathrm{~cm}^{-1}$ and can be assigned to ring C13-C11 and N7-C14 bonds. A strong asymmetric stretch between C14-S2, Cl1 is assigned to the 992 $\mathrm{cm}^{-1}$ band. The observed band at $594 \mathrm{~cm}^{-1}$ is assigned to the out of plane wagging modes of the chlorothiazole ring and other out-of-plane wagging modes are at $443 \mathrm{~cm}^{-1}$ and $358 \mathrm{~cm}^{-1}$. The stretching vibrational mode for the $\mathrm{C} 14-\mathrm{Cl} 1$ bond is seen at $432.6 \mathrm{~cm}^{-1}$ in the SERS spectra and is agreement with the literature data. ${ }^{49}$ Raman peaks at $259 \mathrm{~cm}^{-1}$ and $358 \mathrm{~cm}^{-1}$ are assigned to the weak bending and wagging mode of $\mathrm{C}-\mathrm{Cl}$, respectively.

\section{$\mathrm{N}-\mathrm{O}, \mathrm{N}-\mathrm{H}$ and $\mathrm{C}-\mathrm{N}$ Vibrations}

The N9-0 symmetric and asymmetric stretching vibrations occur at $1318 \mathrm{~cm}^{-1}$ and $1570 \mathrm{~cm}^{-1}$, respectively, which are typical for nitroalkane stretching as reported in the literature. ${ }^{49-50}$ The wagging out of plane vibration of N9-O appears at $754 \mathrm{~cm}^{-1}$; while the $\mathrm{N} 9-0$ rocking occurs at $358 \mathrm{~cm}^{-1}$. There is a strong N9-N6 stretching mode at $992 \mathrm{~cm}^{-1}$ and a C12-N6 stretch at $1152 \mathrm{~cm}^{-1}$.

The $\mathrm{C} 12-\mathrm{N}$ wagging mode is found at $669 \mathrm{~cm}^{-1}$ and the $\mathrm{C} 12-\mathrm{N}$ bending mode is observed at $1318 \mathrm{~cm}^{-1}$. The N8-C15 stretching modes are found at $651 \mathrm{~cm}^{-1}, 947 \mathrm{~cm}^{-1}$ and $1051 \mathrm{~cm}^{-1}$. The Raman band at 310 $\mathrm{cm}^{-1}$ shows a bending mode involving N5, C12 and 04. Similar bending and wagging vibrations are also seen at $443 \mathrm{~cm}^{-1}$. The out of plane $\mathrm{N}-\mathrm{H}$ wagging vibrations (N6H2O and N5H18) are observed at 651 $\mathrm{cm}^{-1}, 514 \mathrm{~cm}^{-1}$ and $577 \mathrm{~cm}^{-1}$. The in-plane N-H bending modes are observed at 1051, 1248, 1318, 1422 and $1532 \mathrm{~cm}^{-1}$.

\section{SERS of Clothianidin}

The SERS of clothianidin solutions was investigated using our SERS substrates. Figure $2 b$ shows the SERS spectra for $(10 \mu \mathrm{g} / \mathrm{mL})$ of clothianidin. The major peaks are well resolved and the large characteristic peaks compare well to the bulk Raman spectrum. These SERS peaks were matched to the Raman active vibrational modes assigned in Table 1. We expect a shift in wavenumber for the SERS peaks for a solution compared to the bulk Raman spectrum. This is due to the adsorption of clothianidin to the SERS substrate Ag surface via nitrogen atoms in the nitroguanidine structure. The largest shifts in the vibrational modes of the SERS spectra were for those modes involving the atoms in the nitroguanidine moiety. This is typical when employing surface enhanced Raman techniques. 
(a)

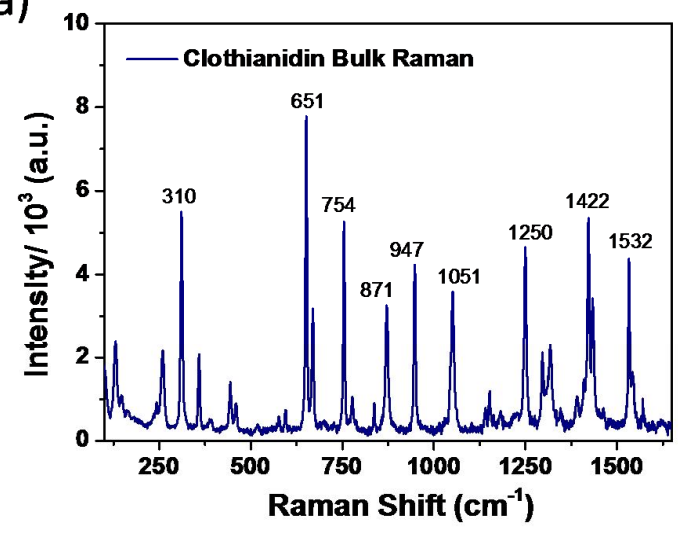

(b)

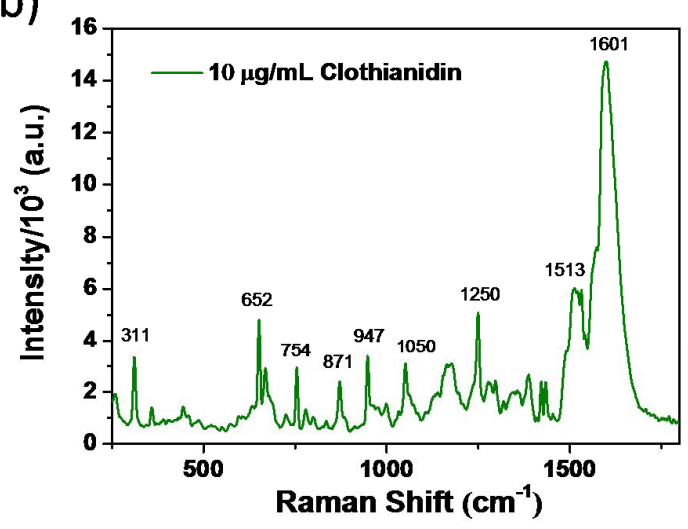

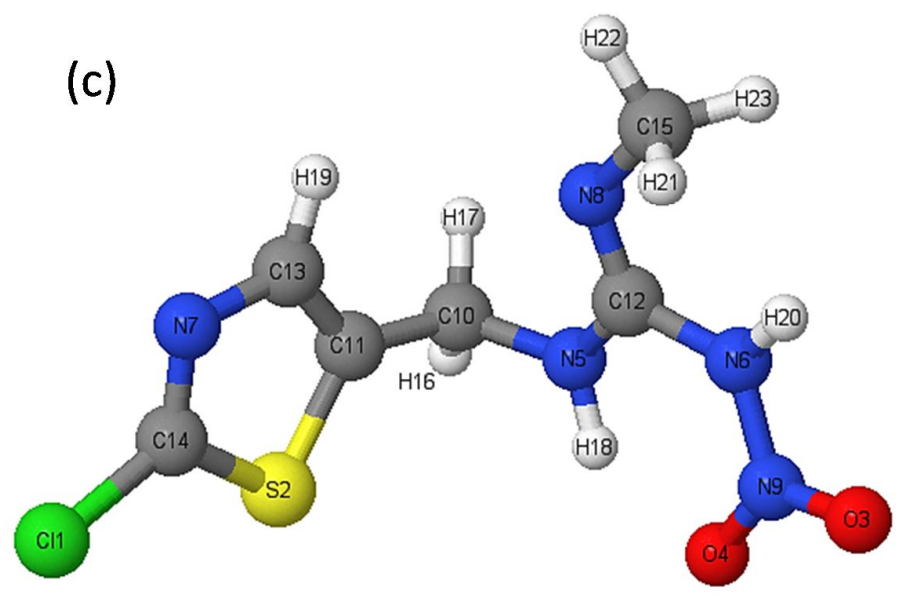

Figure 2: (a) Bulk Raman spectrum and (b) SERS spectrum $(10 \mu \mathrm{g} / \mathrm{mL})$ of clothianidin using fabricated silver coated PVDF substrates. (c) Atomic structure of Clothianidin with atomic numbering.

\begin{tabular}{|c|c|c|c|}
\hline $\begin{array}{l}\text { Raman / } \\
\mathrm{cm}^{-1}\end{array}$ & $\begin{array}{l}\text { SERS (1ng) } \\
/ \mathrm{cm}^{-1}\end{array}$ & $\begin{array}{l}\text { DFT (scaled) / } \\
\text { cm }^{-1}\end{array}$ & Mode Assignments \\
\hline 1570 & 1605 & $1669 / 1604$ & vN9O3O4 as; $8 \mathrm{~N} 6 \mathrm{H} 20 ; 8 \mathrm{~N} 5 \mathrm{H} 18$ \\
\hline 1532 & 1557 & 1517.25 & vC11C13; vC10C11; 8C13H19 (ip); 8N5H18; vN7C14; \\
\hline 1433 & & 1413.35 & vN7C14; vC11C13; $\tau \mathrm{ClOH} 17,18$ \\
\hline 1422 & 1423 & 1403 & $\delta \mathrm{C} 15 \mathrm{H} 21-23 ; \delta \mathrm{N} 6 \mathrm{H} 20$ \\
\hline 1318 & 1335 & 1317 & $\begin{array}{l}\text { vN6N9; vN9O3,4 sym; } \delta N 8 C 12 N 5 N 6 ; \delta C 5 H 18 \text { (ip); } \omega \mathrm{ClOH} 16 \\
\text { (oop) }\end{array}$ \\
\hline 1296 & 1304 & 1297 & $\delta \mathrm{C} 10 \mathrm{C} 11 \mathrm{C} 13 ; \tau \mathrm{C} 10 \mathrm{H} 16,17$ (oop); $\delta \mathrm{C} 13 \mathrm{H} 19$ \\
\hline 1248 & 1254 & 1237 & 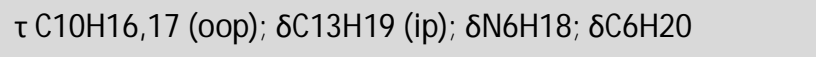 \\
\hline 1152 & 1176 & $1148 / 1126$ & 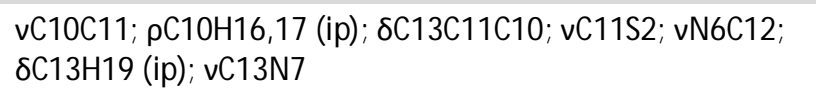 \\
\hline
\end{tabular}




\begin{tabular}{|c|c|c|c|}
\hline 1051 & 1047 & 1051.46 & vHC15N8; vC10N5; 8N5H18 (ip); тC10H16,17 (oop); \\
\hline 992 & 997 & 997.65 & $\begin{array}{l}\text { vN15N19; vN90304 sym; wC15H21-24; vC14S2Cl1 as; } \\
\text { 8N7C14C13H19 }\end{array}$ \\
\hline 947 & 946 & 931.8 & $\rho \mathrm{C} 10 \mathrm{H} 16,17$ (ip); $\delta \mathrm{N} 5 \mathrm{H} 18$ (ip); vC15N8; $\delta \mathrm{C} 10 \mathrm{C} 11 \mathrm{C} 13$ \\
\hline 871 & & 867.64 & $\omega \mathrm{Cl3H} 19$ (oop) \\
\hline 754 & 758 & 750.01 & $\omega N 6 N 90304$ \\
\hline 669 & & 678 & $\begin{array}{l}\omega \mathrm{Cl2N} 5 \mathrm{~N} 6 \mathrm{~N} 8 ; \omega \mathrm{Cl2N} 5 \mathrm{C} 10 \mathrm{C} 11 ; \rho \mathrm{ClOH} 16,17 ; \text { vS2C11C14 as; } \\
\omega \mathrm{C} 13 \mathrm{H} 19\end{array}$ \\
\hline 651 & 650 & 671.83 & $\begin{array}{l}\text { 8N5C12C10H; } \omega N 5 H 18 \text { (oop); vS2C11C14 sym; vHN6N9O3; } \\
\text { vN8C15 }\end{array}$ \\
\hline 594 & 573 & 589 & $\begin{array}{l}\omega \mathrm{Cl0C11C13;} \omega \mathrm{HC13N7C14;} \text { wC11C13N7C14; } \\
\omega \mathrm{Cl3N} 7 \mathrm{C} 14 \mathrm{Cl} 1\end{array}$ \\
\hline 577 & 556 & 545.78 & $\omega N 6 \mathrm{H} 20 ; \omega \mathrm{N} 5 \mathrm{H} 18 ; \omega \mathrm{S} 2 \mathrm{C} 11 \mathrm{C} 14 ; \mathrm{vC14Cl}$ \\
\hline 514 & 522 & 514 & $\omega \mathrm{N} 6 \mathrm{H} 20 ; \omega \mathrm{N} 5 \mathrm{H} 18$ \\
\hline 443 & 432 & 453 & 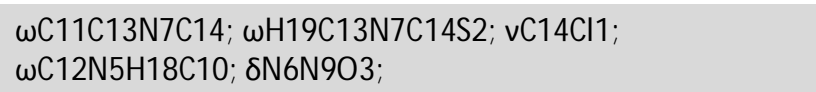 \\
\hline 358 & 358 & 339.41 & $\begin{array}{l}\text { } N 90304 ; \omega C 13 N 7 C 14 C 11 ; \omega C 14 C l 1 ; \omega H C 10 ; \delta C 12 N 6 N 9 ; \\
\omega C 10 C 11 S 2 ; \omega C 12 N 5 C 10 C 11\end{array}$ \\
\hline 310 & 310 & 292.69 & $\delta \mathrm{C} 12 \mathrm{~N} 6 \mathrm{~N} 904 ; \delta \mathrm{N} 6 \mathrm{C} 12 \mathrm{~N} 8 \mathrm{C} 15 \mathrm{H} ; \omega \mathrm{C} 12 \mathrm{~N} 5 \mathrm{H} 18 \mathrm{C} 10 ; \delta \mathrm{S} 2 \mathrm{C} 14 \mathrm{Cl} 1$ \\
\hline 259 & 238 & 237.97 & $\rho \mathrm{C} 10 \mathrm{H} 16,17 ; \delta \mathrm{S} 2 \mathrm{C} 14 \mathrm{Cl} 1 ; \delta \mathrm{N} 8 \mathrm{C} 15 \mathrm{H}$ \\
\hline
\end{tabular}

Table 1: Raman assignations for Clothianidin. The abbreviations are $v$, stretching; $\omega$, wagging; $\tau$, twisting; $\rho$, rocking; $\delta$, bending/scissoring; ip, in plane and oop, out of plane modes. sym and asym denote symmetric and asymmetric modes, respectively.

\subsection{Raman and SERS Analysis of Imidacloprid}

Figure 3 shows the bulk Raman spectrum for Imidacloprid and the SERS detection ( $10 \mu \mathrm{g} / \mathrm{mL}$ solution) in Figure $3 a$ and Figure3b, respectively. The imidacloprid molecule consists of a chloropyridine ring linked with a carbon to an imidazole ring structure. For the purpose of assigning the Raman modes, we name these structures, ring 1 and ring 2, respectively. The structure of imidacloprid, with the atomic numbering used is shown in Figure $3 c$. We again note that here are some spectral differences in the peaks observed in Figure $3 a$ and Figure $3 b$ where there is a change in relative intensities and/or a shift in wavelength. We again speculate that these are due to how the molecule attaches to the surface. Adsorption of the molecules is known to change the energy of the molecule and disrupt the vibrational modes, thus shifting peaks and increasing or decreasing peak intensities. ${ }^{48}$ 
(a)

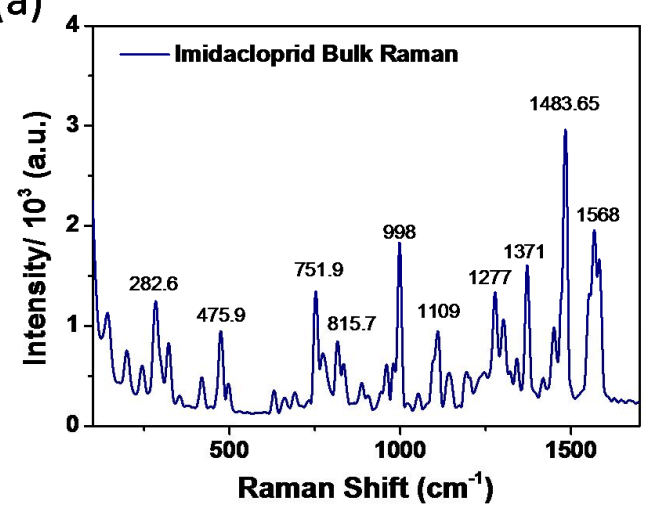

(b)

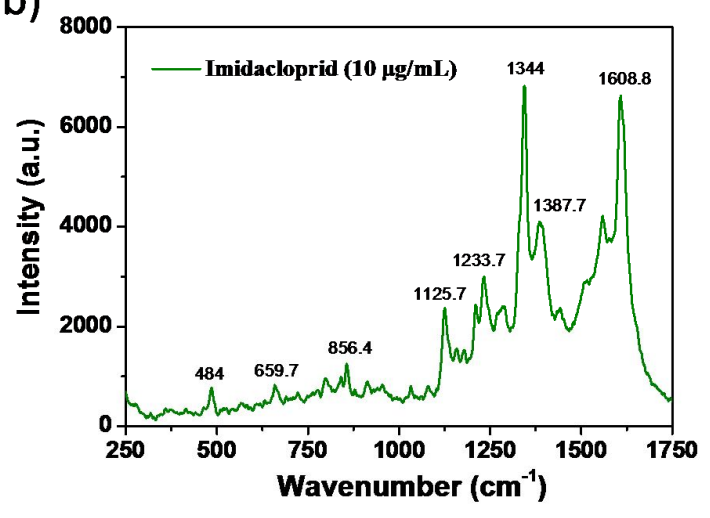

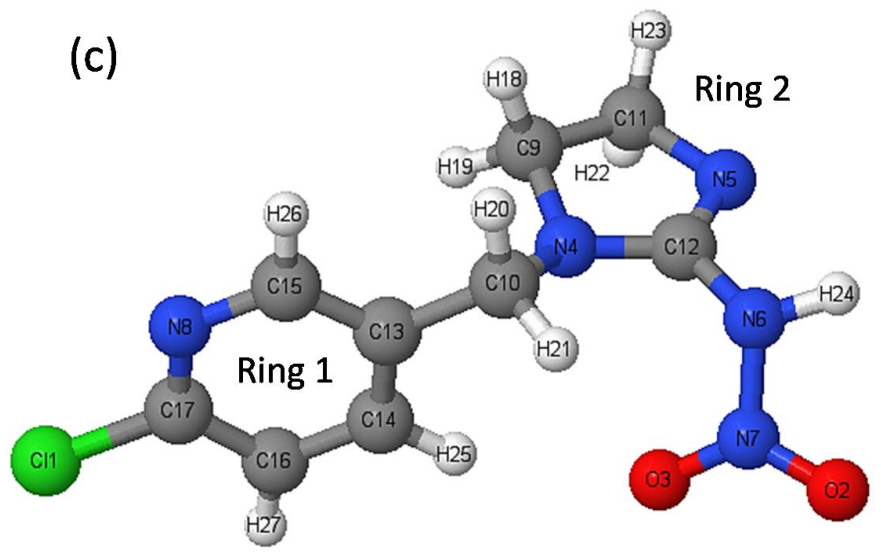

Figure 3: (a) Bulk Raman spectrum and (b) SERS spectrum $(10 \mu \mathrm{g} / \mathrm{mL})$ of imidacloprid using fabricated silver coated PVDF substrates. (c) Structure of imidacloprid with atomic numbering.

The assignments of the key Raman modes are summarised below, and in detail in the SI (Section S3). The Raman spectrum was compared with the SERS spectrum and the DFT results and the assignments are presented in Table 2. ${ }^{51-53}$ Similar to clothianidin, the adsorption of imidacloprid to the SERS substrate will be expected to shift some Raman modes. Typically for molecules that contain a pyridine ring, attachment to the metal surface is via $\mathrm{N}$ in pyridine. ${ }^{54}$ We expect that the largest shifts the SERS spectra will be observed with Raman vibrational frequencies relating to Ring 1 . This is again due to the adsorption of imidacloprid to the SERS substrate Ag surface via nitrogen atoms in the nitroguanidine structure.

\begin{tabular}{llll}
\hline Raman & SERS / & DFT (Scaled) \\
$/ \mathrm{cm}^{-1}$ & $\mathrm{~cm}^{-1}$ & $/ \mathrm{cm}^{-1}$ & Vibrational Assignments \\
\hline
\end{tabular}




\begin{tabular}{|c|c|c|c|}
\hline 1584 & 1607 & $1632 / 1606$ & vC12N4N5N6 as; סN6H24; vN702O3 as \\
\hline 1568 & 1568 & $1575 / 1547$ & CCC Stretching: vC13C14C15 as; vC17N8C16 as \\
\hline 1483 & 1464 & 1483.3 & $\delta \mathrm{C} 9 \mathrm{H} 19, \mathrm{H} 18 ; \delta \mathrm{C} 11 \mathrm{H} 23, \mathrm{H} 22$ \\
\hline 1451 & & 1448.909319 & vC16C17C14 as; vC17N8; $8 \mathrm{HCl} 4 ; \delta H C 15 ; \delta H C 16 ; \delta C 10 \mathrm{H} 20, \mathrm{H} 21$ \\
\hline 1371 & 1387 & 1376 & $v C 16 C 17 C 14$ sym; vC15N8C13 sym; $\omega \mathrm{C} 10 \mathrm{H} 20 \mathrm{H} 21$ \\
\hline 1302 & 1334 & $1320 / 1282$ & $\begin{array}{l}\omega \mathrm{C} 9 \mathrm{H} 19 \mathrm{H} 18 ; \omega \mathrm{C} 11 \mathrm{H} 22 \mathrm{H} 23 ; \omega \mathrm{C} 10 \mathrm{H} 2 \mathrm{OH} 21 ; \delta \mathrm{C} 14 \mathrm{H} 25 ; \mathrm{vN} 702 \mathrm{O} 3 \\
\text { sym }\end{array}$ \\
\hline 1277 & 1327 & 1279.75 & 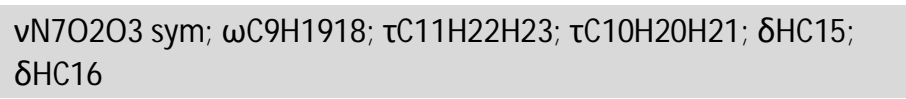 \\
\hline 1241 & 1298. & 1253.77 & $\begin{array}{l}\text { Ring } 1 \text { stretching; } \mathrm{\tau C} 10 \mathrm{H} 20 \mathrm{H} 21 ; \omega \mathrm{C} 9 \mathrm{H} 1918 ; \omega \mathrm{C} 11 \mathrm{H} 22 \mathrm{H} 23 ; \\
\text { vC12N4N5N6 as; vN6N7 }\end{array}$ \\
\hline 1195 & 1233 & 1217.61 & $\tau \mathrm{C} 9 \mathrm{H} 18 \mathrm{H} 19 ; \tau \mathrm{C} 11 \mathrm{H} 22 \mathrm{H} 23$ \\
\hline 1142 & 1190 & 1197 & $\begin{array}{l}v \mathrm{C} 10 \mathrm{Cl3} ; \mathrm{vC10C13C14C15} \text { as; } \omega \mathrm{C} 10 \mathrm{H} 20 ; \omega \mathrm{C} 14 \mathrm{H} 25 ; \omega \mathrm{C} 15 \mathrm{H} 26 ; \\
\omega \mathrm{Cl} 16 \mathrm{H} 27\end{array}$ \\
\hline 1109 & 1125 & 1125.97 & $\delta \mathrm{H} 25 \mathrm{C} 14 \mathrm{C} 16 \mathrm{H} 27 ; \mathrm{vC14C16}$ \\
\hline 998 & 987 & 1008.09 & $\delta C 17 C 16 N 8 ; \delta C 13 C 14 C 15$ \\
\hline 815 & 856 & 815.11 & 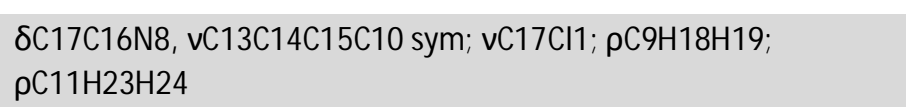 \\
\hline 751 & 740 & 768.22 & 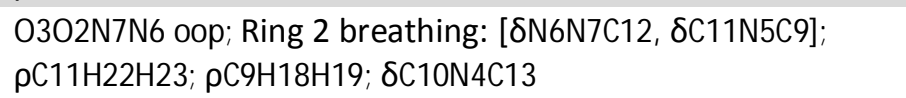 \\
\hline 691 & 677 & 683 & $\begin{array}{l}\text { C12N4N5N6 oop; pC9C11-H sym; } \delta C 10 N 4 ; \\
\text { Ring } 1 \text { breathing: [ } \delta \mathrm{C} 10 \mathrm{C} 14 \mathrm{C} 15, \mathrm{vC} 17 \mathrm{Cl} 1]\end{array}$ \\
\hline 660 & 661 & $662 / 654$ & 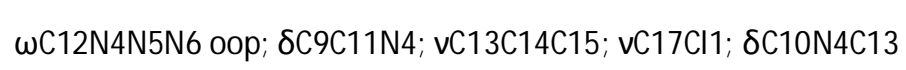 \\
\hline 631 & 635 & 622 & $\delta \mathrm{N} 8 \mathrm{C} 17 \mathrm{C} 15 ; \delta \mathrm{C} 14 \mathrm{C} 13 \mathrm{C} 16 ; \delta \mathrm{C} 12 \mathrm{~N} 4 \mathrm{C} 9 \mathrm{C} 11$ \\
\hline 475 & 484 & 453 & 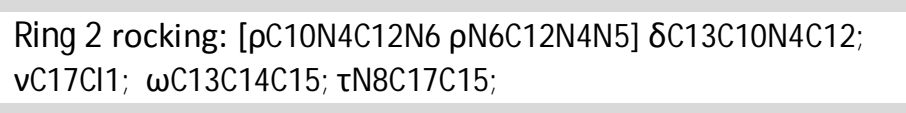 \\
\hline 320 & 320 & 306 & $\omega N 4 C 12 N 5 ; \delta N 4 C 10 C 9$ oop, $\delta C 12 N 5 N 16] ; \delta C 12 N 6 N 703$ \\
\hline 282 & 282 & 274 & $\rho \mathrm{C} 10 \mathrm{H} 2 \mathrm{OH} 21 ; \rho \mathrm{Cl} 1 \mathrm{H} 22 \mathrm{H} 23 ; \delta \mathrm{C} 17 \mathrm{Cl} 1$ \\
\hline 142 & 133 & 144.91 & 8N6N703; $\rho \mathrm{Cl1H} 22 \mathrm{H} 23 ; \rho \mathrm{C} 10 \mathrm{C} 13 \mathrm{~N} 4$ \\
\hline
\end{tabular}

Table 2: Raman and SERS assignations for imidacloprid. The abbreviations are $v$, stretching; $\omega$, wagging; $\tau$, twisting; $\rho$, rocking; $\delta$, bending/scissoring; ip, in plane and oop, out of plane modes sym and asym denote symmetric and asymmetric modes, respectively. 


\section{C-H vibrations}

The stretching modes for $\mathrm{C} 14, \mathrm{C} 15$ and $\mathrm{C} 16 \mathrm{C}-\mathrm{H}$ bonds are visible in the extended spectral range at frequencies above $-3000 \mathrm{~cm}^{-1}$, see Figure $\mathrm{S} 4$ in the $\mathrm{Sl}$, which is typical for $\mathrm{C}-\mathrm{H}$ hetero-aromatic stretching vibrations. ${ }^{55}$ The in-plane bending vibrations are observed at $1451 \mathrm{~cm}^{-1}, 1371 \mathrm{~cm}^{-1}$ and $1277 \mathrm{~cm}^{-1}$ while out of plane wagging modes for the pyridine ring (ring 1) are observed at $1142 \mathrm{~cm}^{-1}$.

Raman modes at $2951 \mathrm{~cm}^{-1}$ and $2970 \mathrm{~cm}^{-1}$ correspond to $\mathrm{C}-\mathrm{H}$ symmetric and asymmetric stretching modes involving $\mathrm{C} 9 \mathrm{H}$ and $\mathrm{C} 11 \mathrm{H}$. The strong in plane bending vibration for $\mathrm{C} 9-\mathrm{H}$ and $\mathrm{C} 11-\mathrm{H}$ appears as at $1484 \mathrm{~cm}^{-1}$. A twisting vibrational mode was also observed at $1195 \mathrm{~cm}^{-1}$. Finally, multiple $\mathrm{C}-\mathrm{H}$ and $\mathrm{C} 11-\mathrm{H}$ in-plane rocking modes were observed at $815 \mathrm{~cm}^{-1}, 751 \mathrm{~cm}^{-1}, 691 \mathrm{~cm}^{-1}$ and $142 \mathrm{~cm}^{-1}$. The $\mathrm{Cl0}$ symmetric stretching modes with $\mathrm{H} 21$ and $\mathrm{H} 20$ were observed at $3008 \mathrm{~cm}^{-1}$ and $2878 \mathrm{~cm}^{-1}$, respectively. The only $\mathrm{C} 10 \mathrm{H}$ bending vibration is found at $1451 \mathrm{~cm}^{-1}$.

Ring Vibrations

Raman modes at $1568 \mathrm{~cm}^{-1}, 1451 \mathrm{~cm}^{-1}$ and $1371 \mathrm{~cm}^{-1}$ are attributed to two asymmetric and one symmetric stretching modes in ring 1 . Other stretching modes in Ring 1 are observed at $1142 \mathrm{~cm}^{-1}$ and $815 \mathrm{~cm}^{-1}$.

The peaks at $998 \mathrm{~cm}^{-1}$ and $691 \mathrm{~cm}^{-1}$ are attributed to weak ring bending vibrations in Ring 1. Finally, the Raman peak at $631 \mathrm{~cm}^{-1}$ arises from a strong symmetric bending mode of $\mathrm{C} 14$ with $\mathrm{C} 13 / \mathrm{C} 16$ and N8 with $\mathrm{C} 15 / \mathrm{C} 17$. The Raman band at $476 \mathrm{~cm}^{-1}$ is attributed to wagging of $\mathrm{C} 13$ and $\mathrm{C} 17$ atoms out of plane in ring 1.

Due to the orientation of imidacloprid, the majority of the imidazole ring vibrational modes (ring 2) are observed as out-of plane vibrations. In-plane rocking and breathing modes are observed at 475 $\mathrm{cm}^{-1}$ and $751 \mathrm{~cm}^{-1}$, respectively. The $320 \mathrm{~cm}^{-1}$ band is assigned as a ring wagging. A strong $\mathrm{C} 12-\mathrm{N}$ asymmetric stretch is observed at $1584 \mathrm{~cm}^{-1}$ and a weaker asymmetric stretch is at $1241 \mathrm{~cm}^{-1}$. The common C12-N wagging vibrations are at $691 \mathrm{~cm}^{-1}$ and $660 \mathrm{~cm}^{-1}$.

\section{$\mathrm{N}-\mathrm{O}$ and $\mathrm{C}-\mathrm{N}$ Vibrations}

The N7-O symmetric and asymmetric stretching vibrations occur at $1302 \mathrm{~cm}^{-11}$ and $1584 \mathrm{~cm}^{-1}$, respectively. These are two well resolved bands in both the Raman and SERS spectra, and compare well to the nitroalkane stretching mode reported in the literature. ${ }^{55}$ The out of plane wagging vibration of N7-O is observed at $751 \mathrm{~cm}^{-1}$; while the bending vibration of N6-N7-02-03 occurs at $142 \mathrm{~cm}^{-1}$. The 
N6-N7 stretching mode is observed at $1241 \mathrm{~cm}^{-1}$, with a second strong stretching mode at $\sim 1050 \mathrm{~cm}^{-}$ 1. A strong in-plane $\mathrm{N} 6 \mathrm{~N} 702$ bending mode is seen at $443 \mathrm{~cm}^{-1}$.

\subsection{SERS Detection of Neonicotinoids}

Having demonstrated that SERS is able to discriminate the presence of our target neonicotinoids at high concentrations, we explore the use of SERS for the qualitative detection of clothianidin and imidacloprid in solution at low concentrations that are relevant for the allowed concentrations of neonicitinoids, and we show SERS detection down to $1 \mathrm{ng} / \mathrm{mL}$. The SERS spectrum of clothianidin is shown in

(a)

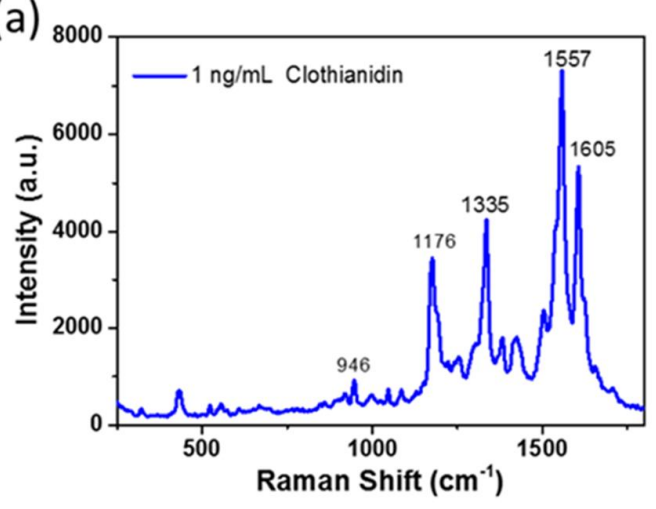

(b)

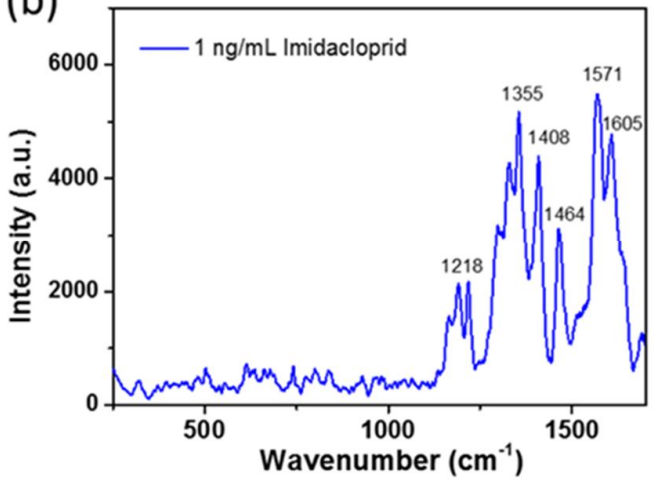

Figure 4a.

Although the Raman peaks are not particularly well resolved or strong at below $940 \mathrm{~cm}^{-1}$, there are clear strong peaks at 946, 1176, 1335, 1557 and $1605 \mathrm{~cm}^{-1}$, which correspond to the previously established characteristic peaks of clothianidin at 947, 1152, 1318, 1532 and $1570 \mathrm{~cm}^{-1}$ in the Raman spectrum. These peaks therefore act as a fingerprint for the presence of clothianidin in solution. This finding demonstrates that clothianidin can be detected by our SERS sensors at these previously unreachable concentrations using a simple drop and dry method.

In a similar manner, the SERS spectrum for a solution of $1 \mathrm{ng} / \mathrm{mL}$ of imidacloprid is presented 
(a)

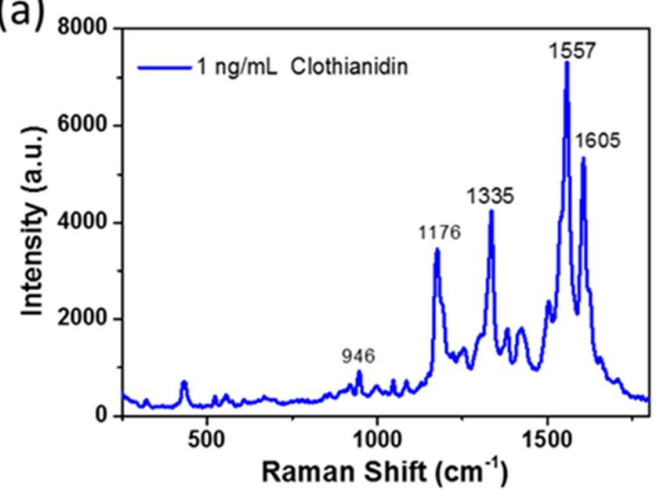

(b)

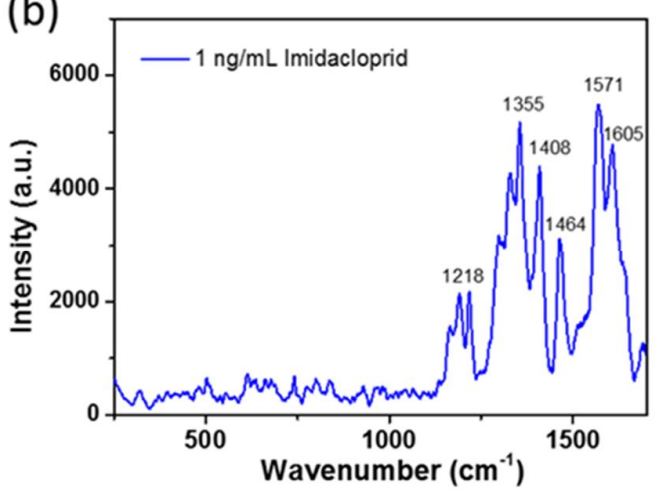

Fiqure 4b. Again the peaks at high wavenumbers, beyond $1200 \mathrm{~cm}^{-1}$ which correspond to the characteristic peaks of the molecule, are well resolved. Bands at 1218, 1355, 1408, 1464, 1571 and $1605 \mathrm{~cm}^{-1}$, labelled in

(a)

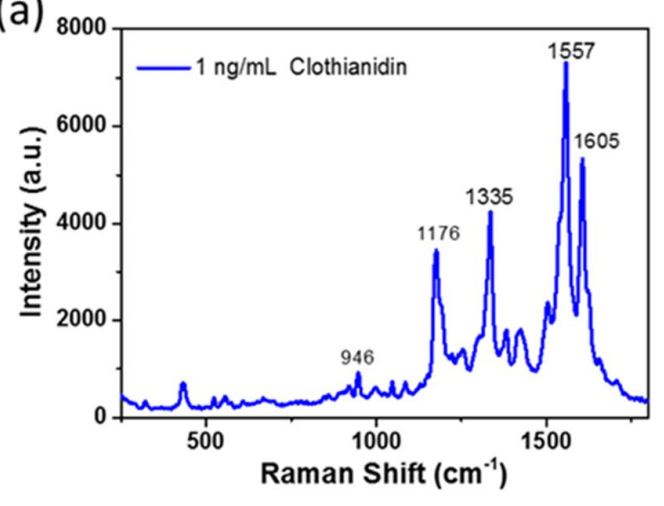

(b)

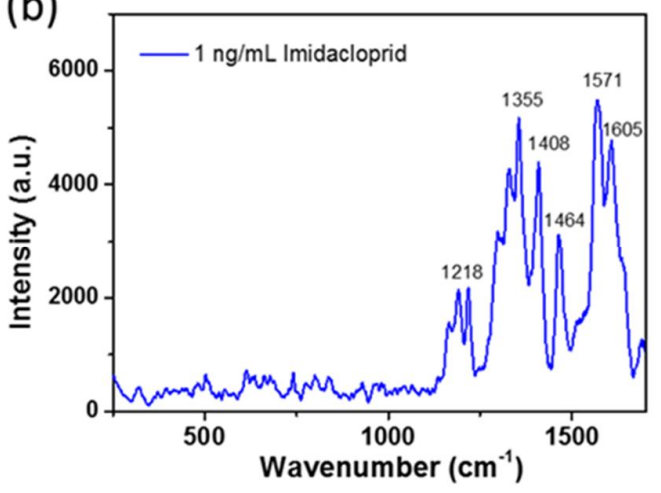

Figure 4b, are similar to those in the bulk Raman spectrum (refer back to Figure 2a). They are mainly attributed to the bending and wagging of the ring structures in imidacloprid. A key result is that minimum detection concentration that we achieved is significantly lower than the current lowest legal residue limit of ca. $10 \mathrm{ng} / \mathrm{mL}$ for food products ${ }^{56}$ which demonstrates the power of SERS technique for the detection of neonicotinoid residues. 

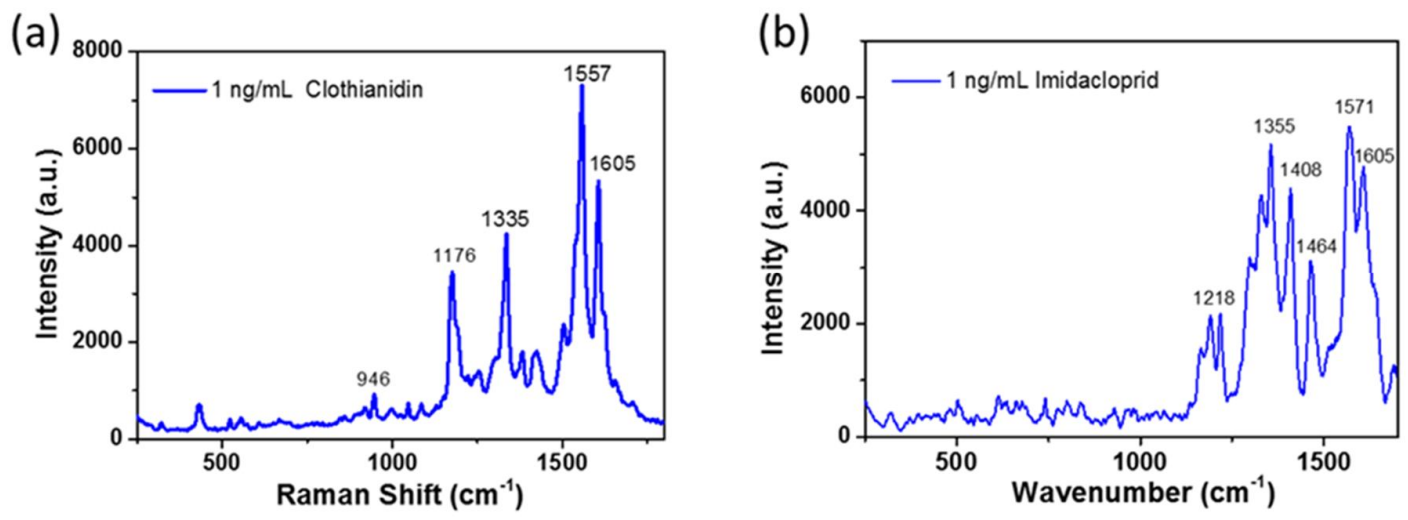

Figure 4: SERS detection of (a) clothianidin and (b) imidacloprid at $1 \mathrm{ng} / \mathrm{mL}$ using the fabricated silver coated PVDF substrates.

Comparing Figure $4 a$ with Figure $2 \mathrm{~b}$, at $1 \mathrm{ng} / \mathrm{mL}$, peaks at 1176,1335 , and $1557 \mathrm{~cm}^{-1}$ are very large and clear in Figure $4 \mathrm{a}$, but at $10 \mu \mathrm{g} / \mathrm{mL}$, these peaks are very hard to identify. This is especially evident for the $1557 \mathrm{~cm}^{-1}$ peak, which is the largest peak in Figure 4a, but it is hard to identify in Figure 2b. to explain this, we and others have observed that the concentration of an analyte influences the intensities of the observed peaks - this is a key reason why quantitative measurements with Raman spectroscopy is difficult ${ }^{48}$. A reproducible dependence of the SERS intensity on the analyte concentration can only be obtained for a certain dynamic range which appears to be dependent on what molecule is being measured, the plasmonic metal being used (and how it is prepared) and the nature of the hotspots. This deviation from the low-concentration relation between SERS intensity and concentration is assumed to be due to the influence of the adsorption geometry, which becomes important if the amount of adsorbant increases. In SERS, there is the additional complication of the orientation of the molecule on the surface. All this can change the selection rules for Raman and will lead to some vibrations being enhanced, some disappearing and some shifting. Specially in the drop and dry method as described in this paper. If the concentration is high, it is possible that at the 10 $\mu \mathrm{g} / \mathrm{mL}$ molecules will tend to recrystallize upon drying. Therefore, the SERS for higher concentration could/ would be an enhancement of the bulk (i.e. small crystals trapped in hot spots), and the observed SERS spectrum will be closer to the bulk one. When concentration decreases, then SERS more likely to be single or few molecules, and therefore bigger changes vs bulk Raman (compounded by orientation). Furthermore, it must be noted that the intensities are stated in arbitrary units and since each substrate has variations in density of hot spots, some sections may provide a higher response to others. 


\subsection{Comparison with other Techniques}

The results for neonicotinoid detection obtained using our nanowire array SERS devices are compared against literature reports and Table 3 presents typical limits of detection. The measured limit of detection for the present SERS devices is a significant improvement over solid state electrochemical measurements and on a par with results achieved using high-end laboratory instrumentation, but with the advantage of low cost and potential in situ use of the sensor devices. The use of SERS to detect the presence of these neonicotinoids gives a very useful, accurate, and potentially in-situ, analytical tool and clearly demonstrates the viability of this approach to the selective detection of neonicotinoid species.

\begin{tabular}{|c|c|c|c|c|}
\hline Detection method & Electrode Type/ Diameter & Neonicotinoid & LOD & Ref \\
\hline \multirow{2}{*}{$\begin{array}{l}\text { Enzyme-linked } \\
\text { immunosorbent assays }\end{array}$} & - & Imidacloprid & $20 \mathrm{nM}$ & 20 \\
\hline & - & Clothianidin & $11 \mathrm{nM}$ & 57 \\
\hline $\begin{array}{l}\text { Gas Chromatography - } \\
\text { Mass Spectroscopy }\end{array}$ & - & Clothianidin & $40 \mathrm{nM}$ & 28 \\
\hline \multicolumn{2}{|l|}{$\begin{array}{l}\text { Tandem Mass } \\
\text { Spectrometry }\end{array}$} & Clothianidin & $40 \mathrm{nM}$ & 58 \\
\hline \multirow{3}{*}{$\begin{array}{l}\text { High performance liquid } \\
\text { chromatography }\end{array}$} & - & Imidacloprid & $90 \mathrm{nM}$ & 59 \\
\hline & - & Imidacloprid & $39 \mathrm{nM}$ & 60 \\
\hline & - & Clothianidin & $10 \mathrm{nM}$ & 61 \\
\hline \multirow{5}{*}{$\begin{array}{l}\text { Differential-Pulse } \\
\text { Voltammetry }\end{array}$} & Bismuth-Film Modified GCE & Clothianidin & $3000 \mathrm{nM}$ & 62 \\
\hline & Carbon paste electrode $(\mathrm{d}=2 \mathrm{~mm})$ & Imidacloprid & $2030 \mathrm{nM}$ & 59 \\
\hline & Hanging Mercury drop electrode & Imidacloprid & $2560 \mathrm{nM}$ & 63 \\
\hline & Nanosilver/SDS GCE (d =3 mm) & Imidacloprid & $250 \mathrm{nM}$ & 64 \\
\hline & Hanging Mercury drop electrode & Imidacloprid & $39 \mathrm{nM}$ & 65 \\
\hline \multirow[t]{3}{*}{ Cyclic voltammetry } & Glassy carbon Electrode (GCE) & Imidacloprid & $10.9 \mu \mathrm{M}$ & 27 \\
\hline & Nanosilver/SDS GCE ( $\mathrm{d}=3 \mathrm{~mm}$ ) & Imidacloprid & $630 \mathrm{nM}$ & 64 \\
\hline & $\begin{array}{l}\text { Reduced graphene oxide GCE }(\mathrm{d}= \\
3 \mathrm{~mm})\end{array}$ & Imidacloprid & $400 \mathrm{nM}$ & 66 \\
\hline \multirow{2}{*}{$\begin{array}{l}\text { Square wave } \\
\text { Voltammetry }\end{array}$} & Silver-Amalgam Film Electrode & Clothianidin & $2080 \mathrm{nM}$ & 67 \\
\hline & Hanging Mercury drop electrode & Imidacloprid & $16 \mathrm{nM}$ & 26 \\
\hline \multirow{4}{*}{$\begin{array}{l}\text { Surface Enhanced Raman } \\
\text { Spectroscopy (SERS) }\end{array}$} & & Imidacloprid & $19.5 \mathrm{nM}$ & 68 \\
\hline & & Imidacloprid & $40 \mathrm{nM}$ & 69 \\
\hline & & Clothianidin & \multicolumn{2}{|c|}{ Not reported previously } \\
\hline & & $\begin{array}{l}\text { Imidacloprid } \\
\text { Clothianidin }\end{array}$ & $\begin{array}{l}4 \mathrm{nM} \\
4 \mathrm{nM}\end{array}$ & $\begin{array}{l}\text { This } \\
\text { work }\end{array}$ \\
\hline
\end{tabular}

Table 3: Comparison of detection methods for clothianidin and imidacloprid in the literature compared with our results. 


\section{Conclusion}

The use of Surface Enhanced Raman Spectroscopy in the development of low cost, portable sensor devices that can be used in the field for nitroguanidine neonicotinoid insecticide detectionis appealing. To make progress towards this goal, this paper presents an analysis of the bulk Raman and SERS spectra of two neonicotinoids, namely clothianidin and imidacloprid, together with the use of SERS to demonstrate the sensing of these molecules.

Silver nanostructured surfaces were fabricated for qualitative SERS, which provides the characteristic spectra of the target molecules. Combined with first principles simulations, this allowed assignment of all Raman spectral modes for both molecules. To our knowledge, this is the first report of SERS analysis and vibrational assignment of Clothianidin and we demonstrate SERS detection neonicotinoid insecticide at concentration s as low as $1 \mathrm{ng} / \mathrm{mL}$.

These measured detection concentrations are significantly lower than reported solid state electrochemical techniques and are on par with high-end chromatographic-mass spectroscopy laboratory methods. These SERS sensors thus allow for the selective and sensitive detection of neonicotinoids and provides complimentary qualitative data for the molecules. Furthermore, this technique can be adapted to portable devices for remote sensing applications. Further work focuses on integrating our device with an electronics platform for truly portable residue detection. Future work will focus on translating this method to samples with complex matrices. As neonicotinoids are banned in Ireland, we cannot test real samples, but we intend to use these substrates to test spiked river water/ farm run off for neonicotinoids. Principal component analysis methods will be employed to deconvolute spectra obtained from complex matrices.

\section{Supporting Information}

The Supporting Information is available free of charge at https://pubs.acs.org/ doi/10.1021/acs.xxxxx. SERS sensor Characterisation with Crystal Violet, full Clothianidin vibrational analysis, full imidacloprid vibrational analysis (PDF).

\section{Acknowledgments}

This publication has emanated from research supported in part by a research grant from Science Foundation Ireland (SFI) under Connect (13/RC/2077), the VistaMilk Centre Science Foundation Ireland (SFI); Department of Agriculture Food and the Marine (DAFM) under Grant Number 16/RC//3835, the Technology Innovation Development Award (SFI/12/TIDA12377) and Environmental Protection Agency UisceSense (EPA 2015-W-M S-21) 


\section{References}

1. Elbert, A.; Haas, M.; Springer, B.; Thielert, W.; Nauen, R., Applied aspects of neonicotinoid uses in crop protection. Pest Management Science 2008, 64 (11), 1099-1105.

2. Jeschke, P.; Nauen, R., Neonicotinoids-from zero to hero in insecticide chemistry. Pest Management Science 2008, 64 (11), 1084-1098.

3. Nauen, R.; Bretschneider, T., New modes of action of insecticides. Pesticide Outlook 2002, 13 (6), 241-245.

4. Tomizawa, M.; Casida, J. E., Neonicotinoid insecticide toxicology: mechanisms of selective action. Annual Review of Pharmacology and Toxicology 2005, 45, 247-268.

5. Henry, M.; Beguin, M.; Requier, F.; Rollin, O.; Odoux, J.-F.; Aupinel, P.; Aptel, J.;

Tchamitchian, S.; Decourtye, A., A common pesticide decreases foraging success and survival in honey bees. Science 2012, 336 (6079), 348-350.

6. Whitehorn, P. R.; O'Connor, S.; Wackers, F. L.; Goulson, D., Neonicotinoid pesticide reduces bumble bee colony growth and queen production. Science 2012, 336 (6079), 351-352.

7. M Miligi, L.; Costantini, A. S.; Veraldi, A.; Benvenuti, A.; Will; Vineis, P., Cancer and Pesticides. Annals of the New York Academy of Sciences 2006, 1076 (1), 366-377.

8. M einert, R.; Schüz, J.; Kaletsch, U.; Kaatsch, P.; M ichaelis, J., Leukemia and non-Hodgkin's lymphoma in childhood and exposure to pesticides: results of a register-based case-control study in Germany. American Journal of Epidemiology 2000, 151 (7), 639-646.

9. Betarbet, R.; Sherer, T. B.; M acKenzie, G.; Garcia-Osuna, M.; Panov, A. V.; Greenamyre, J. T., Chronic systemic pesticide exposure reproduces features of Parkinson's disease. Nature Neuroscience 2000, 3 (12), 1301-1306.

10. Salameh, P.; Baldi, I.; Brochard, P.; Raherison, C.; Saleh, B. A.; Salamon, R., Respiratory symptoms in children and exposure to pesticides. European Respiratory Journal 2003, 22 (3), 507512.

11. Kimura-Kuroda, J.; Komuta, Y.; Kuroda, Y.; Hayashi, M.; Kawano, H., Nicotine-like effects of the neonicotinoid insecticides acetamiprid and imidacloprid on cerebellar neurons from neonatal rats. PloS one 2012, 7 (2), e32432.

12. Duzguner, V.; Erdogan, S., Acute oxidant and inflammatory effects of imidacloprid on the mammalian central nervous system and liver in rats. Pesticide Biochemistry and Physiology 2010, 97 (1), 13-18.

13. Hanke, W.; Jurewicz, J., The risk of adverse reproductive and developmental disorders due to occupational pesticide exposure: an overview of current epidemiological evidence. International Journal of Occupational M edicine and Environmental Health 2004, 17 (2), 223-243.

14. Blacquiere, T.; Smagghe, G.; van Gestel, C. A.; M ommaerts, V., Neonicotinoids in bees: a review on concentrations, side-effects and risk assessment. Ecotoxicology 2012, 21 (4), 973-92.

15. Wood, T. J.; Goulson, D., The environmental risks of neonicotinoid pesticides: a review of the evidence post 2013. Environmental Science and Pollution Research 2017, 24 (21), 17285-17325.

16. European Commission, Commission Implementing Regulation (EU) No 485/2013 of 24 May 2013 amending Implementing Regulation (EU) No 540/2011, as regards the conditions of approval of the active substances clothianidin, thiamethoxam and imidacloprid, and prohibiting the use and sale of seeds treated with plant protection products containing those active substances. Official J ournal of the European Union 2013, 139, 12-14.

17. Ferrer, I.; Thurman, E. M.; Fernández-Alba, A. R., Quantitation and Accurate Mass Analysis of Pesticides in Vegetables by LC/TOF-M S. Analytical Chemistry 2005, 77 (9), 2818-2825.

18. European Food Safety Authority, The 2014 European Union Report on Pesticide Residues in Food. EFSA Journal 2016, 14 (10), e04611-n/a. 
19. European Food Safety Authority, Peer review of the pesticide risk assessment for bees for the active substance clothianidin considering the uses as seed treatments and granules. EFSA Journal 2018, 16 (2), e05177.

20. Lee, J. K.; Ahn, K. C.; Park, O. S.; Kang, S. Y.; Hammock, B. D., Development of an ELISA for the Detection of the Residues of the Insecticide Imidacloprid in Agricultural and Environmental Samples. Journal of Agricultural and Food Chemistry 2001, 49 (5), 2159-2167.

21. Watanabe, E.; Baba, K.; Eun, H.; M iyake, S., Application of a commercial immunoassay to the direct determination of insecticide imidacloprid in fruit juices. Food Chemistry 2007, 102 (3), 745750.

22. Obana, H.; Okihashi, M.; Akutsu, K.; Kitagawa, Y.; Hori, S., Determination of Acetamiprid, Imidacloprid, and Nitenpyram Residues in Vegetables and Fruits by High-Performance Liquid Chromatography with Diode-Array Detection. Journal of Agricultural and Food Chemistry 2002, 50 (16), 4464-4467.

23. Liu, S.; Zheng, Z; Wei, F.; Ren, Y.; Gui, W.; Wu, H.; Zhu, G., Simultaneous Determination of Seven Neonicotinoid Pesticide Residues in Food by Ultraperformance Liquid Chromatography Tandem M ass Spectrometry. Journal of Agricultural and Food Chemistry 2010, 58 (6), 3271-3278.

24. Aguera, A.; Almansa, E.; Malato, S.; Maldonado, M.; Fernandez-Alba, A., Evaluation of photocatalytic degradation of imidacloprid in industrial water by GC-M S and LC-MS. Analysis 1998, 26 (7), 245-251.

25. Navalón, A.; González-Casado, A.; El-Khattabi, R.; Vilchez, J. L.; Fernández-Alba, A. R., Determination of imidacloprid in vegetable samples by gas chromatography-mass spectrometry. Analyst 1997, 122 (6), 579-581.

26. Guiberteau, A.; Galeano, T.; M ora, N.; Parrilla, P.; Salinas, F., Study and determination of the pesticide Imidacloprid by square wave adsorptive stripping voltammetry. Talanta 2001, 53 (5), 943949.

27. Guzsvány, V. J.; Gaál, F. F.; Bjelica, L. J.; Ökrész, S. N., Voltammetric determination of imidacloprid and thiamethoxam. Journal of the Serbian Chemical Society 2005, 70 (5), 735-743.

28. Li, L.; Jiang, G.; Liu, C.; Liang, H.; Sun, D.; Li, W., Clothianidin dissipation in tomato and soil, and distribution in tomato peel and flesh. Food Control 2012, 25 (1), 265-269.

29. Papp, Z; Guzsvány, V.; Svancara, I.; Vytras, K., Carbon paste electrodes for the analysis of some agricultural pollutants and trace metals. Journal of Agricultural Science and Technology 2011, 5 (1), 85-92.

30. Ví Ichez, J. L.; Valencia, M. C.; Navalón, A.; MolineroM orales, B.; Capitán-Vallvey, L. F., Flow injection analysis of the insecticide imidacloprid in water samples with photochemically induced fluorescence detection. Analytica Chimica Acta 2001, 439 (2), 299-305.

31. Lovera, P.; Creedon, N.; Alatawi, H.; Mitchell, M.; Burke, M.; Quinn, A. J.; O'Riordan, A., Lowcost silver capped polystyrene nanotube arrays as super-hydrophobic substrates for SERS applications. Nanotechnology 2014, 25 (17), 175502.

32. Albrecht, M. G.; Creighton, J. A., Anomalously intense Raman spectra of pyridine at a silver electrode. Journal of the American Chemical Society 1977, 99 (15), 5215-5217.

33. Fleischmann, M.; Hendra, P. J.; M cQuillan, A. J., Raman spectra of pyridine adsorbed at a silver electrode. Chemical Physics Letters 1974, 26 (2), 163-166.

34. Otto, A.; M rozek, I.; Grabhorn, H.; Akemann, W., Surface-enhanced Raman scattering. Journal of Physics: Condensed Matter 1992, 4 (5), 1143.

35. Stiles, P. L.; Dieringer, J. A.; Shah, N. C.; Duyne, R. P. V., Surface-Enhanced Raman Spectroscopy. Annual Review of Analytical Chemistry 2008, 1 (1), 601-626.

36. Creedon, N. C.; Lovera, P.; Furey, A.; O'Riordan, A., Transparent polymer-based SERS substrates templated by a soda can. Sensors and Actuators B: Chemical 2018, 259, 64-74.

37. Becke, A. D., Density-functional thermochemistry. III. The role of exact exchange. The J ournal of chemical physics 1993, 98 (7), 5648-5652. 
38. Weigend, F.; Ahlrichs, R., Balanced basis sets of split valence, triple zeta valence and quadruple zeta valence quality for $\mathrm{H}$ to $\mathrm{Rn}$ : Design and assessment of accuracy. Physical Chemistry Chemical Physics 2005, 7 (18), 3297-3305.

39. Ma, C.; Zaino III, L. P.; Bohn, P. W., Self-induced redox cycling coupled luminescence on nanopore recessed disk-multiscale bipolar electrodes. Chemical science 2015, 6 (5), 3173-3179.

40. Grimme, S., Semiempirical GGA-type density functional constructed with a long-range dispersion correction. Journal of computational chemistry 2006, 27 (15), 1787-1799.

41. Peng, C.; Ayala, P. Y.; Schlegel, H. B.; Frisch, M. J., Using redundant internal coordinates to optimize equilibrium geometries and transition states. Journal of Computational Chemistry 1996, 17 (1), 49-56.

42. Deglmann, P.; Furche, F.; Ahlrichs, R., An efficient implementation of second analytical derivatives for density functional methods. Chemical physics letters 2002, 362 (5-6), 511-518.

43. Deglmann, P.; Furche, F., Efficient characterization of stationary points on potential energy surfaces. The Journal of Chemical Physics 2002, 117 (21), 9535-9538.

44. Merrick, J. P.; M oran, D.; Radom, L., An evaluation of harmonic vibrational frequency scale factors. The Journal of Physical Chemistry A 2007, 111 (45), 11683-11700.

45. Khaikin, L. S.; Grikina, O. E.; Lokshin, B. V.; Dyugaev, K. P.; Astakhov, A. M., Vibrational spectra of 1,1,3,3-tetramethyl-2-nitroguanidine and their interpretation with the use of scaling of quantum-chemical force field. Russian Chemical Bulletin 2008, 57 (3), 499-505.

46. Zhang, F.; Zhang, Y.; Ni, H.; Ma, K.; Li, R., Experimental and DFT studies on the vibrational, electronic spectra and NBO analysis of thiamethoxam. Spectrochimica Acta Part A: Molecular and Biomolecular Spectroscopy 2014, 118, 162-171.

47. Jalkanen, J.-P.; Zerbetto, F., Interaction model for the adsorption of organic molecules on the silver surface. The Journal of Physical Chemistry B 2006, 110 (11), 5595-5601.

48. Sackmann, M.; M aterny, A., Surface enhanced Raman scattering (SERS) - a quantitative analytical tool? Journal of Raman Spectroscopy: An International Journal for Original Work in all Aspects of Raman Spectroscopy, Including Higher Order Processes, and also Brillouin and Rayleigh Scattering 2006, 37 (1-3), 305-310.

49. Socrates, G., Infrared and Raman Characteristic Group Frequencies: Tables and Charts. John Wiley \& Sons: 2001.

50. Zhu, X.-M.; Zhang, S.-Q.; Zheng, X.; Phillips, D. L., Resonance Raman study of short-time photodissociation dynamics of the charge-transfer band absorption of nitrobenzene in cyclohexane solution. The Journal of Physical Chemistry A 2005, 109 (13), 3086-3093.

51. Markham, L. M.; M ayne, L. C.; Hudson, B. S.; Zgierski, M. Z, Resonance Raman studies of imidazole, imidazolium, and their derivatives: the effect of deuterium substitution. The Journal of Physical Chemistry 1993, 97 (40), 10319-10325.

52. Sundaraganesan, N.; Ilakiamani, S.; Anand, B.; Saleem, H.; Joshua, B. D., FTIR, FT-Raman spectra and ab initio DFT vibrational analysis of 2-amino-5-chloropyridine. Spectrochimica Acta Part A: Molecular and Biomolecular Spectroscopy 2006, 64 (3), 586-594.

53. Kumar, M.; Srivastava, M.; Yadav, R. A., Vibrational studies of benzene, pyridine, pyridine-Noxide and their cations. Spectrochimica Acta Part A: Molecular and Biomolecular Spectroscopy 2013, $111,242-251$.

54. Chen, L.; Gao, Y.; Xu, H.; Wang, Z; Li, Z.; Zhang, R.-Q., The mechanism of N-Ag bonding determined tunability of surface-enhanced Raman scattering of pyridine on $\mathrm{MAg}(\mathrm{M}=\mathrm{Cu}, \mathrm{Ag}, \mathrm{Au})$

diatomic clusters. Physical Chemistry Chemical Physics 2014, 16 (38), 20665-20671.

55. Lin-Vien, D.; Colthup, N. B.; Fateley, W. G.; Grasselli, J. G., The handbook of infrared and Raman characteristic frequencies of organic molecules. Elsevier: 1991.

56. European Food Safety Authority, The 2011 European Union Report on Pesticide Residues in Food. EFSA Journal 2014 2014, 12 (5), 3694. 
57. Li, M.; Sheng, E.; Cong, L.; Wang, M., Development of Immunoassays for Detecting Clothianidin Residue in Agricultural Products. Journal of Agricultural and Food Chemistry 2013, 61 (15), 3619-3623.

58. Kim, B. M.; Park, J.-S.; Choi, J.-H.; Abd El-Aty, A. M.; Na, T. W.; Shim, J.-H., Residual determination of clothianidin and its metabolites in three minor crops via tandem mass spectrometry. Food Chemistry 2012, 131 (4), 1546-1551.

59. Papp, Z.; Švancara, I.; Guzsvány, V.; Vytřas, K.; Gaál, F., Voltammetric determination of imidacloprid insecticide in selected samples using a carbon paste electrode. Microchim Acta 2009, 166 (1-2), 169-175.

60. Obana, H.; Okihashi, M.; Akutsu, K.; Kitagawa, Y.; Hori, S., Determination of Neonicotinoid Pesticide Residues in Vegetables and Fruits with Solid Phase Extraction and Liquid Chromatography Mass Spectrometry. Journal of Agricultural and Food Chemistry 2003, 51 (9), 2501-2505.

61. Chen, M.-F.; Huang, J.-W.; Wong, S.-S.; Li, G.-C., Analysis of insecticide clothianidin and its metabolites in rice by liquid chromatography with a UV detector. Journal of Food and Drug Analysis 2005, 13 (3), 279-283.

62. Guzsvány, V.; Papp, Z.; Zbiljić, J.; Vajdle, O.; Rodić, M., Bismuth Modified Carbon-Based Electrodes for the Determination of Selected Neonicotinoid Insecticides. Molecules 2011, 16 (6), 4451.

63. Kashid, L.; Pawar, N., Voltammetric behaviour of imidacloprid and its electrochemical mineralization assessment by differential pulse polarography. International Journal of Scientific and Research Publications 2015.

64. Kumaravel, A.; Chandrasekaran, M., Electrochemical determination of imidacloprid using nanosilver Nafion $₫$ nanoTiO2 Nafion $\circledast$ composite modified glassy carbon electrode. Sensors and Actuators B: Chemical 2011, 158 (1), 319-326.

65. Navalón, A.; El-Khattabi, R.; González-Casado, A.; Vilchez, J., Differential-pulse polarographic determination of the insecticide imidacloprid in commercial formulations. Microchim Acta 1999, 130 (4), 261-265.

66. Kong, L.; Jiang, X.; Zeng, Y.; Zhou, T.; Shi, G., M olecularly imprinted sensor based on electropolmerized poly(o-phenylenediamine) membranes at reduced graphene oxide modified electrode for imidacloprid determination. Sensors and Actuators B: Chemical 2013, 185 (0), 424-431. 67. Brycht, M.; Vajdle, O.; Zbiljić, J.; Papp, Z.; Guzsvány, V.; Skrzypek, S., Renewable SilverAmalgam Film Electrode for Direct Cathodic SWV Determination of Clothianidin, Nitenpyram and Thiacloprid Neonicotinoid Insecticides Reducible in a Fairly Negative Potential Range. International Journal of Electrochemical Science 2012, 7 (11).

68. Hou, R.; Pang, S.; He, L., In situ SERS detection of multi-class insecticides on plant surfaces. Analytical Methods 2015, 7 (15), 6325-6330.

69. Zhang, H.; Kang, Y.; Liu, P.; Tao, X.; Pei, J. W.; Li, H.; Du, Y. P., Determination of Pesticides by Surface-Enhanced Raman Spectroscopy on Gold-Nanoparticle-M odified Polymethacrylate. Analytical Letters 2016, 49 (14), 2268-2278. 
Table of Contents Graphic

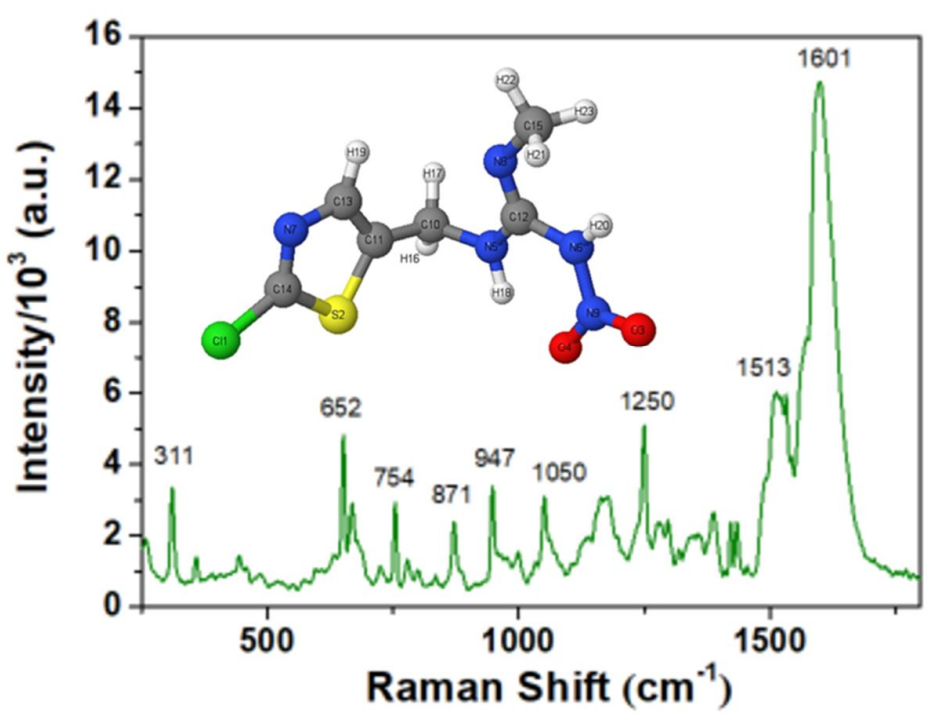

